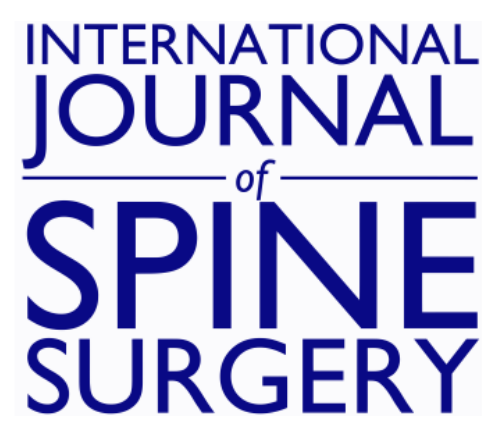

\title{
Thoracic and lumbar vertebrae morphology in Lenke type 1 female adolescent idiopathic scoliosis patients
}

Xiaobang Hu, Krzysztof B. Siemionow and Isador H. Lieberman

Int J Spine Surg 2014, 8 ()

doi: https://doi.org/10.14444/1030

http://ijssurgery.com/content/8/30

This information is current as of April 26, 2023.

Email Alerts Receive free email-alerts when new articles cite this article. Sign up at:

http://ijssurgery.com/alerts 


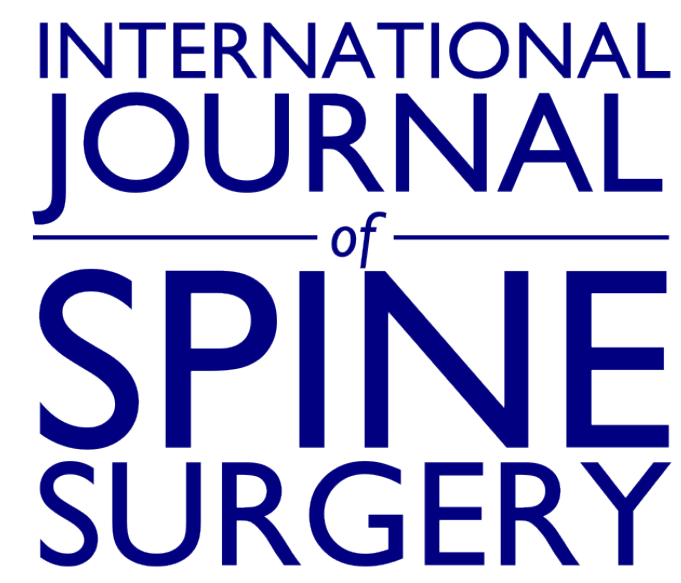

This article generously published free of charge by the International Society for the Advancement of Spine Surgery.

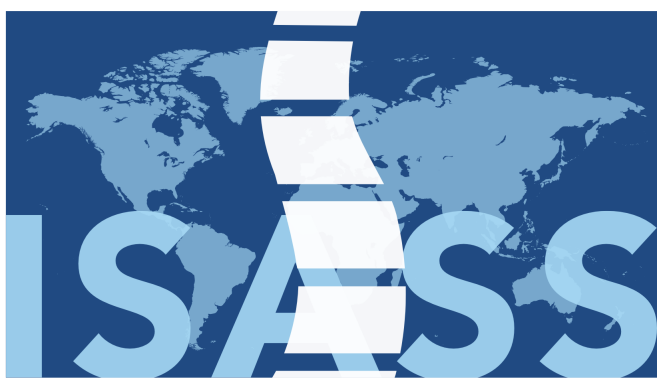

INTERNATIONAL SOCIETY for the ADVANCEMENT of SPINE SURGERY 


\section{Thoracic and lumbar vertebrae morphology in Lenke type 1 female adolescent idiopathic scoliosis patients}

Xiaobang Hu, MD, PhD, ${ }^{l}$ Krzysztof B. Siemionow, MD, ${ }^{2}$ Isador H. Lieberman, MD, MBA, FRCSC ${ }^{1}$

${ }^{1}$ Scoliosis and Spine Tumor Center, Texas Back Institute, Texas Health Presbyterian Hospital

Plano, Plano, TX 75093, USA, ${ }^{2}$ Department of Orthopaedic Surgery, University of Illinois Medical Center, Chicago, IL 60612 USA

\section{Abstract}

\section{Background}

Pedicle screws are widely used in adolescent idiopathic scoliosis (AIS) surgeries. Pedicle screw malposition may lead to serious vascular and neurologic complications. Knowledge of the morphometric anatomy of the thoracic and lumbar vertebrae is essential for the surgeon while implanting pedicle screws. It has been reported that there is a reduction of pedicle width at the concavity of the curve in AIS patients. However, it is unclear if gender plays a role in this pedicle width pattern. The goal of this study is to assess the vertebrae morphology in a more homogeneous group of AIS patients - female patients with Lenke type 1 curve.

\section{Methods}

The thoracic and lumbar vertebra and pedicle morphometry of 17 consecutive Lenke type 1 female AIS patients was analyzed based on $1 \mathrm{~mm}$ fine cut CT scans. Morphometric anatomy of 539 pedicles from T1 to L5 was studied. Measurements included pedicle length, chord length, transverse pedicle width, transverse pedicle angle and vertebral rotation angle.

\section{Results}

The mean age of the patients was 14 years old (range 12-18). The mean Cobb angle was $56^{\circ}$ (range $43^{\circ}-88^{\circ}$ ) and the mean angle of vertebral rotation varied between $4-13.8^{\circ}$. The apical vertebra was between $\mathrm{T} 7$ and $\mathrm{T} 11$. The transverse pedicle width was significantly smaller $(\mathrm{p}<0.05)$ on the concave side in the apical region of the thoracic spine (T7 and T8), measuring between 2.1-2.2 $\mathrm{mm}$ on the concave side and 2.7-3.1 $\mathrm{mm}$ on the convex side. Meanwhile, in some upper thoracic vertebrae (T3, T4, T5), the width was significantly bigger $(\mathrm{p}<0.05)$ on the concave side than on the convex side, measuring between 2.8-4 mm on the concave side and 1.8-2.4 mm on the convex side. In the lumbar spine, the width varied between 4.1-9.9 mm without significant differences between the 
concave and convex sides ( $p>0.05)$. The pedicle length varied between 15.4-28.7 mm and was significantly smaller $(\mathrm{p}<0.05)$ on the concave side at T4, T5 and L2. The chord length was shortest at $\mathrm{T} 1$, measuring $32.4 \mathrm{~mm}$ and increased gradually to $54.3 \mathrm{~mm}$ at L3 but no statistical difference was found between the concave and convex sides. The transverse pedicle angle varied between $11.8^{\circ}$ and $35^{\circ}$ and was significantly bigger on the concave side at $\mathrm{T} 7$ and on the convex side at $\mathrm{L} 1(\mathrm{p}<0.05)$.

\section{Conclusions}

The vertebrae morphology in Lenke type 1 female AIS patients is substantially different from the vertebrae in normal spines especially at the apex and in the upper thoracic region. This is consistent with some previous reports which did not distinguish between male and female patients. Our findings suggest that gender does not play a major role in the vertebrae morphology pattern of AIS patients. Furthermore, recognizing this pattern is critical in order to optimize pedicle screw instrumentation and may allow for some leeway adjustments in the pedicle screw trajectory regardless of the methods of implantation.

keywords: Pedicle screw, Vertebrae morphology, Adolescent idiopathic scoliosis, Female, Lenke classification Volume 8 Article 30 doi: 10.14444/1030

\section{Introduction}

Adolescent idiopathic scoliosis (AIS) is present in 2\% to 4\% of children between 10 and 16 years of age. ${ }^{1}$ It is recognized as a complex three-dimensional (3D) deformation of the spine with lateral deviation in the coronal plane, alternation of the kyphosis/lordosis in the sagittal plane and rotation of the vertebrae in the axial plane.

Pedicle screw instrumentation has been widely used in the surgeries for AIS patients. ${ }^{2-4} \mathrm{~A}$ thorough understanding of vertebrae anatomy is crucial for safe pedicle screw implantation. The misplacement of pedicle screws may lead to severe complications, such as vascular and neurologic injuries and the complication rate has been reported to range from $1 \%$ up to $54 \% .{ }^{5-10}$ Vertebral morphology of the normal spine has been extensively studied and has provided valuable information regarding pedicle screw instrumentation. ${ }^{11-17}$

Identification and classification of AIS deformity plays an important role in the surgeon's decision making when surgical intervention is considered. The most appropriate levels of segmental instrumentation can be determined based on the identification of the patient's scoliosis pattern and classification. Likewise, the most appropriate trajectory and starting point for screw insertion can be predetermined by knowledge and familiarity with the anatomy. The Lenke scoliosis classification system was widely adopted as a guide for selection of levels for surgical treatment of AIS and it classifies scoliosis into six basic curve types depending on the structurality and dominance of these segments. ${ }^{21}$ 
There have been some studies on the vertebral morphology in AIS patients. ${ }^{18-20}$ It is reported that there is a reduction of pedicle width at the concavity of the curve in AIS patients. However, it is unclear if gender plays a role in this pedicle width pattern. The goal of this study is to evaluate the vertebrae morphology in a more homogeneous group of AIS patients - female patients with Lenke type 1 curve.

\section{Materials and Methods}

A single surgeon's operative scoliosis database was used to identify all the AIS cases. Preoperative standing anterior-posterior (AP) and lateral radiographs, left and right side bending radiographs were reviewed. Coronal and sagittal curves were measured using the Cobb method. Flexibility of the thoracic and lumbar scoliotic curves was assessed from preoperative standing and bending radiographs. The criteria in the Lenke classification chart was used to determine the scoliosis curve type. Lenke curve type I patients were identified based on the specific characteristics in PA and lateral radiographs. ${ }^{21}$

Vertebral body morphology including pedicle parameters were measured in all patients from pre-operative thin-cut $(1 \mathrm{~mm}) \mathrm{CT}$ scans to characterize the anatomic dimensions. The CT scan is a standard procedure done for the preoperative planning of robotic assisted pedicle screw placement. The measurements included pedicle length, chord length, transverse pedicle width, transverse pedicle angle and angle of vertebral rotation. The pedicle length was measured as the distance from the posterior cortical entry point of the pedicle to the posterior longitudinal ligament along the axis of the pedicle. The chord length was measured as the distance between the posterior cortical entry point of the pedicle and the anterior vertebral cortex in line with the axis of the pedicle. The transverse pedicle width was measured as the endosteal width at the narrowest part of the pedicle. The transverse pedicle angle was measured as the angle between a line perpendicular to the transverse isthmus and a sagittal midvertebral line (Figure 1A,B). The angle of vertebral rotation $\left(\mathrm{RA}_{\text {sag }}\right)$ was measured as the angle between the bisector of the bilateral longitudinal spinous-foraminal line and vertical axis (Figure 1C). 


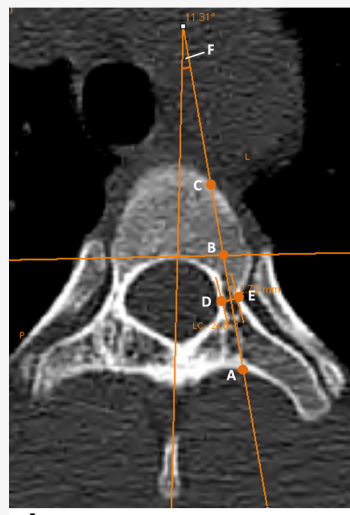

A

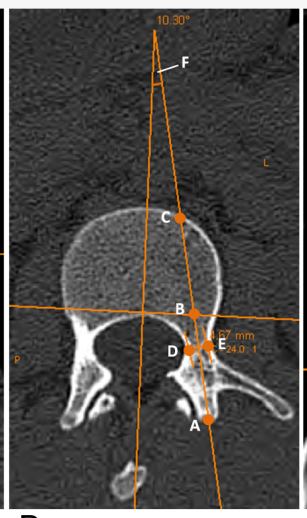

B

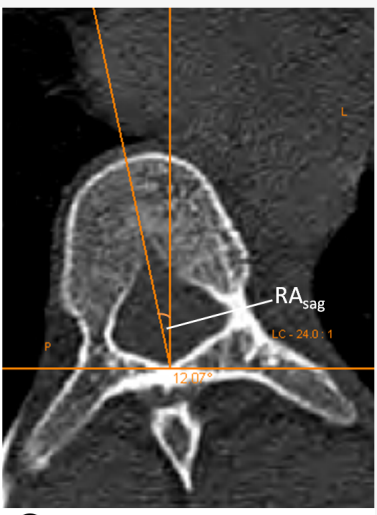

C

Fig. 1. A, Illustration of a thoracic vertebra, showing the pedicle length $(\mathrm{AB})$, the chord length $(\mathrm{AC})$, the transverse pedicle width $(\mathrm{DE})$ and the transverse pedicle angle $(\mathrm{F}) .{ }^{18,24,29,30} \mathrm{~B}$, Illustration of a lumbar vertebra, showing the pedicle length $(\mathrm{AB})$, the chord length $(\mathrm{AC})$, the transverse pedicle width $(\mathrm{DE})$ and the transverse pedicle angle (F). ${ }^{18,24,29,30} \mathrm{C}$, Illustration of the angle of vertebral rotation $\left(\mathrm{RA}_{\mathrm{sag}}\right)$. $\mathrm{RA}_{\text {sag }}$ is defined as the angle between the bisector of the bilateral longitudinal spinous-foraminal line and vertical axis. ${ }^{31-35}$

All the measurements were made directly from the bone window images using the OfficePACS system (version 4.1, Stryker Imaging). All the parameters on the concave side were compared with the corresponding convex side. All the measurements were done in a blinded fashion. The $t$ test was utilized to determine significance. A $p$ value of $<0.05$ was considered significant.

\section{Results}

A total of 17 consecutive female AIS patients were included in this study. The mean age of the patients was 14 years old (range 12-18). The mean Cobb angle was $56^{\circ}$ (range $43^{\circ}$ $-88^{\circ}$ ) and the mean angle of vertebral rotation varied between $4-13.8^{\circ}$. The apical vertebra was between T7 and T11 (Table 1). Thirteen patients had back pain with a mean VAS score of 5 (range 2-9). Four patients had leg pain with a mean VAS score of 3 (range 1-4). Rib humps were prominent in all patients. All patients were treated surgically.

Table 1. Angle of vertebral rotation and apical vertebrae distribution in the studied patients.

\begin{tabular}{|l|l|l|}
\hline Level & Rotation (degrees) & No. Apical Vertebrae \\
\hline T1 & $4 \pm 3$ & \\
\hline T2 & $4.8 \pm 2.4$ & \\
\hline T3 & $7.5 \pm 3.8$ & \\
\hline T4 & $7.4 \pm 4.3$ & \\
\hline T5 & $6.6 \pm 4$ & \\
\hline T6 & $8.2 \pm 4.5$ & 3 \\
\hline T7 & $9.9 \pm 5.8$ & 5 \\
\hline T8 & $12.9 \pm 5.7$ & \\
\hline
\end{tabular}




\begin{tabular}{|l|l|l|l|}
\hline T9 & $13.8 \pm 6.2$ & 6 \\
\hline T10 & $12.6 \pm 7.1$ & 2 \\
\hline T11 & $12.3 \pm 6.5$ & 1 \\
\hline T12 & $11 \pm 5.3$ & \\
\hline L1 & $10.9 \pm 5.9$ & \\
\hline L2 & $10 \pm 6$ & \\
\hline L3 & $9.3 \pm 4.8$ & \\
\hline L4 & $7.8 \pm 4.7$ & \\
\hline L5 & $5.7 \pm 4.2$ & & \\
\hline
\end{tabular}

\section{Transverse Pedicle Width}

In the thoracic spine, the transverse pedicle width was measured between 2.1-5.9 mm on the concave side and $1.8-4.8 \mathrm{~mm}$ on the convex side. In the apical region of the thoracic spine (T7 and T8), the transverse pedicle width was significantly smaller on the concave side with a measurement of 2.1-2.2 $\mathrm{mm}$ on the concave side and 2.7-3.1 $\mathrm{mm}$ on the convex side $(\mathrm{p}<0.05)$. Meanwhile, in three upper thoracic vertebrae (T3, T4, T5), the width was significantly bigger on the concave side than on the convex side, measuring between 2.8-4 mm on the concave side and 1.8-2.4 mm on the convex side $(\mathrm{p}<0.05)$. In the lumbar spine, the transverse pedicle width varied between 4.1-9.9 $\mathrm{mm}$ without significant differences between the concave and convex sides ( $>0.05$ ) (Table 2).

Table 2. Transverse pedicle width and transverse pedicle angle in the studied patients $\left(^{*}\right.$ : $\mathrm{p}<0.05)$.

\begin{tabular}{|c|c|c|c|c|c|c|c|c|}
\hline \multirow[b]{2}{*}{ Level } & \multirow[b]{2}{*}{$\mathbf{n}$} & \multicolumn{3}{|c|}{ Transverse pedicle width (mm) } & \multirow[b]{2}{*}{$\mathbf{n}$} & \multicolumn{3}{|c|}{ Transverse pedicle angle (degrees) } \\
\hline & & Mean & Range & Median & & Mean & Range & Median \\
\hline $\mathrm{T} 1$ concave & 11 & $5.3 \pm 0.9$ & $3.8-6.5$ & 5.7 & 11 & $33.2 \pm 4.8$ & $26.8-42.5$ & 32.6 \\
\hline $\mathrm{T} 1$ convex & 12 & $4.8 \pm 0.9$ & $3.5-5.9$ & 4.9 & 12 & $35 \pm 5$ & $27.6-42.6$ & 34.9 \\
\hline $\mathrm{T} 2$ concave & 16 & $4.5 \pm 1.4$ & $1.9-7.1$ & 5 & 16 & $25.2 \pm 6.6$ & $17.2-40.1$ & 24.8 \\
\hline $\mathrm{T} 2$ convex & 16 & $3.9 \pm 1.2$ & $1.7-6.4$ & 3.8 & 16 & $26.6 \pm 7.2$ & $17.4-42.8$ & 25.6 \\
\hline $\mathrm{T} 3$ concave & 17 & $4 \pm 1.1^{*}$ & $1.9-5.6$ & 3.9 & 17 & $19.8 \pm 6.3$ & $9.7-32.3$ & 18.2 \\
\hline $\mathrm{T} 3$ convex & 17 & $2.4 \pm 1.3$ & $0.9-4.6$ & 2.2 & 17 & $19.3 \pm 6.8$ & $11.3-38.3$ & 17.2 \\
\hline $\mathrm{T} 4$ concave & 17 & $2.9 \pm 0.8^{*}$ & $1.3-4.1$ & 3.1 & 17 & $16.1 \pm 3.9$ & $7.8-23.4$ & 16.7 \\
\hline T4convex & 17 & $1.8 \pm 0.7$ & $0.5-3.4$ & 1.6 & 17 & $15.1 \pm 4.1$ & $8.1-23.6$ & 14.6 \\
\hline T5 concave & 17 & $2.8 \pm 0.7^{*}$ & $1.6-4.1$ & 2.8 & 17 & $15 \pm 3.7$ & $8.6-25.1$ & 14.7 \\
\hline T5 convex & 17 & $1.8 \pm 0.9$ & $0.8-3.7$ & 1.8 & 17 & $15.2 \pm 5$ & $11-33$ & 13.9 \\
\hline $\mathrm{T} 6$ concave & 17 & $2.4 \pm 0.8$ & $0.9-3.7$ & 2.6 & 17 & $14.9 \pm 3.3$ & $10.6-22.1$ & 14.6 \\
\hline T6 convex & 17 & $2.4 \pm 1$ & $1.2-4.4$ & 2.2 & 17 & $14.1 \pm 2.9$ & $8.4-19.6$ & 14.3 \\
\hline $\mathrm{T} 7$ concave & 17 & $2.1 \pm 0.6^{*}$ & $1-3.2$ & 2.1 & 17 & $14.7 \pm 2.8^{*}$ & $9.4-20$ & 14.5 \\
\hline $\mathrm{T} 7$ convex & 17 & $2.7 \pm 0.9$ & $1.5-4.2$ & 2.8 & 17 & $12.8 \pm 2.1$ & $9.4-16.1$ & 12.8 \\
\hline $\mathrm{T} 8$ concave & 17 & $2.2 \pm 0.6^{*}$ & $0.8-2.9$ & 2.4 & 17 & $14 \pm 3.4$ & $9-24.4$ & 13.2 \\
\hline T8 convex & 17 & $3.1 \pm 0.8$ & $1.3-4$ & 3.5 & 17 & $12.9 \pm 2.8$ & $8.3-19.5$ & 13.5 \\
\hline T9 concave & 17 & $2.9 \pm 1.1$ & $1.1-5$ & 2.7 & 17 & $14.5 \pm 2.9$ & $10.9-21.1$ & 14.3 \\
\hline T9 convex & 17 & $3 \pm 0.9$ & $0.9-4.4$ & 3.2 & 17 & $13.8 \pm 2.9$ & $10.3-21.4$ & 13 \\
\hline $\mathrm{T} 10$ concave & 17 & $3.7 \pm 1.3$ & $1.7-6.7$ & 3.7 & 17 & $13 \pm 2.4$ & $9.7-20.4$ & 12.6 \\
\hline T10 convex & 17 & $3.4 \pm 1$ & $1.1-5.2$ & 3 & 17 & $13.9 \pm 2.8$ & $8.6-22.8$ & 13.8 \\
\hline T11 concave & 17 & $4.5 \pm 1.2$ & $2.7-6.6$ & 4.5 & 17 & $11.9 \pm 2.5$ & $7.6-15.6$ & 11.7 \\
\hline T11 convex & 17 & $4 \pm 1.4$ & $2-6.9$ & 3.7 & 17 & $13.3 \pm 3.3$ & $8-22.6$ & 13.1 \\
\hline $\mathrm{T} 12$ concave & 17 & $5.9 \pm 1.5$ & $3.5-9$ & 5.5 & 17 & $11.8 \pm 3.2$ & $6.1-17.6$ & 11.6 \\
\hline
\end{tabular}




\begin{tabular}{|l|l|l|l|l|l|l|l|l|}
\hline T12 convex & 17 & $4.8 \pm 1.9$ & $2.2-7.8$ & 4.4 & 17 & $12.7 \pm 2.9$ & $7.8-17.7$ & 13.1 \\
\hline L1 concave & 17 & $4.9 \pm 1.6$ & $1.6-7.9$ & 5.4 & 17 & $13.2 \pm 3.3 *$ & $7.8-18.8$ & 12.2 \\
\hline L1 convex & 17 & $4.3 \pm 1.6$ & $1.8-7.5$ & 4.3 & 17 & $16 \pm 3.5$ & $7.9-23.7$ & 15.8 \\
\hline L2 concave & 17 & $4.4 \pm 1.3$ & $1.9-7.1$ & 4.1 & 17 & $14.9 \pm 3.6$ & $8.6-22.2$ & 15.5 \\
\hline L2 convex & 17 & $4.1 \pm 1.8$ & $1-7.4$ & 3.9 & 17 & $15.6 \pm 2.9$ & $11.1-21.7$ & 15.3 \\
\hline L3 concave & 15 & $5.5 \pm 1.4$ & $3.4-8.2$ & 6 & 15 & $16.4 \pm 3.5$ & $11.5-24.2$ & 15.1 \\
\hline L3 convex & 15 & $5.5 \pm 2.3$ & $2.8-10.2$ & 5.1 & 15 & $15.6 \pm 3.3$ & $9.6-19.7$ & 16.2 \\
\hline L4 concave & 13 & $7.9 \pm 2.1$ & $5.2-11.2$ & 7.6 & 13 & $20.2 \pm 5.2$ & $13.1-31.7$ & 18.7 \\
\hline L4 convex & 13 & $7.6 \pm 2.1$ & $4.9-10.5$ & 7.6 & 13 & $19.3 \pm 4$ & $14.5-28.2$ & 18 \\
\hline L5 concave & 10 & $9.8 \pm 2.8$ & $5.5-14.8$ & 9.4 & 10 & $27.9 \pm 5.3$ & $18.3-34.8$ & 28.7 \\
\hline L5 convex & 10 & $9.9 \pm 1.8$ & $5.6-12.6$ & 9.9 & 10 & $29.2 \pm 5.5$ & $17.6-37.9$ & 29.2 \\
\hline
\end{tabular}

\section{Transverse Pedicle Angle}

The transverse pedicle angle was highest at the upper thoracic region measuring $33^{\circ}-35^{\circ}$ and lower lumbar region measuring $28^{\circ}-29^{\circ}$. It gradually decreased from T1 to T12 and then increased from L1 to L5. The differences between the concave side and the convex side were minimal except at $\mathrm{T} 7$ and $\mathrm{L} 1$ levels. The angle was significantly bigger on the concave side at $\mathrm{T} 7$ and on the convex side at L1 $(\mathrm{p}<0.05)$ (Table 2).

\section{Pedicle Length}

The pedicle length varied minimally between the concave side and the convex side in both the thoracic and lumbar regions. A significantly shorter pedicle length was found on the concave side at T4, T5 and L2 ( $<<0.05)$ (Figure 2).

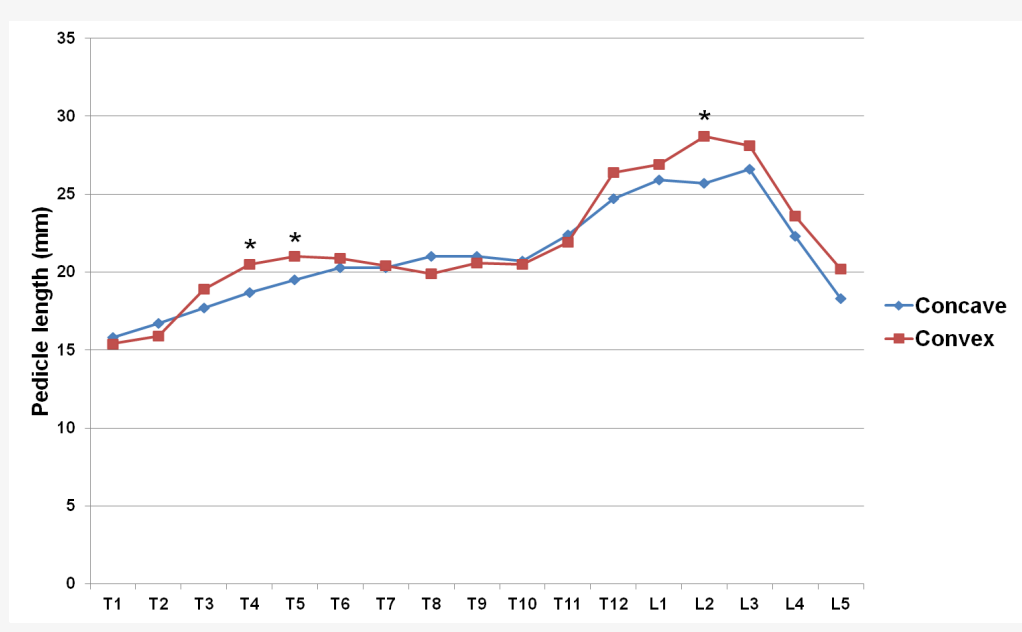

Fig. 2. Pedicle length in the studied patients $(*: p<0.05)$.

\section{Chord Length}

The chord length also varied minimally between the concave side and the convex side in both the thoracic and lumbar regions. The length was shortest at T1, measuring $32.4 \mathrm{~mm}$ and increased gradually to $54.3 \mathrm{~mm}$ at L3. No statistical difference was found between the concave and convex sides at all levels (Figure 3). 


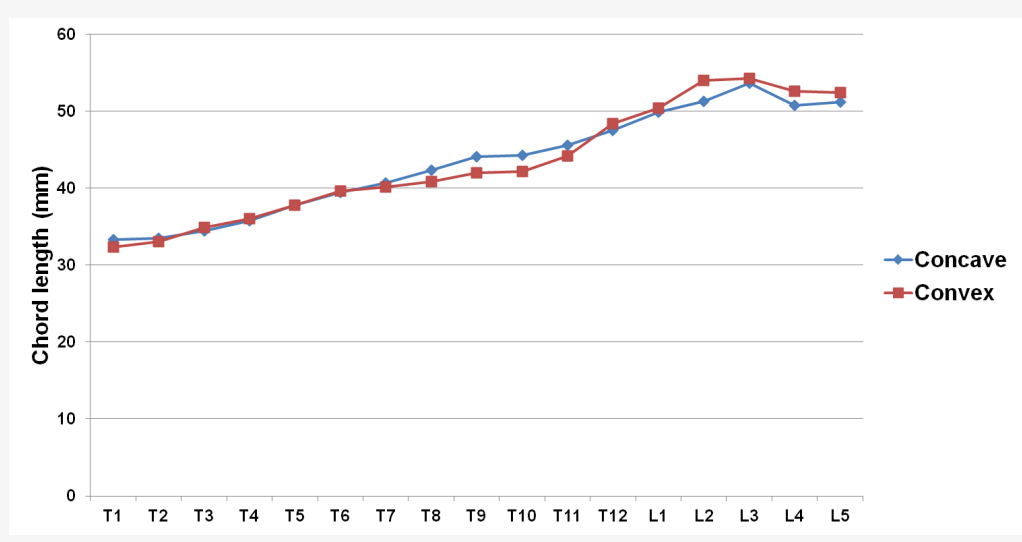

Fig. 3. Chord length in the studied patients.

\section{Discussion}

Pedicle screw instrumentation has become a popular and widely accepted method in the surgeries for AIS patients. Although some newly developed navigation techniques may help the surgeons to place pedicle screws more safely, it is still very important that the spine surgeon has a clear knowledge of the pedicle morphometric anatomy especially in deformed spines to optimize starting point and trajectory of the screw path.

Transverse pedicle width is an important factor which determines the diameter of screws that can be safely accommodated in a pedicle without breaching the lateral and medial cortex. In this study, we found that for Lenke type 1 AIS female patients, the transverse pedicle width was significantly smaller on the concave side than the convex side in the apical region of the thoracic spine. In a previous study, Parent et al. examined the thoracic pedicle morphology in 325 cadaveric scoliotic vertebrae and they also found that pedicles located on the concavity of typical right thoracic curves were significantly thinner than the convex side and the maximal mean difference was found at T8. ${ }^{22}$ Recently, AbulKasim et al. studied the pedicle width pattern in Lenke type 1 AIS patients and they reported similar findings. ${ }^{23} \mathrm{We}$ also found that in the upper thoracic vertebrae, the transverse pedicle width was significantly wider on the concave side which can also be identified as the convex side of the compensatory curve. Abul-Kasim et al. also reported a similar pattern in their study. ${ }^{23}$

Meanwhile, in the lumbar spine, there is no significant difference for the transverse pedicle width between the concave and convex sides. This may relate to the fact that the lumbar curve in Lenke type 1 AIS patients are secondary curves. Similar findings have been reported by Liljenqvist et al. ${ }^{24}$

Transverse pedicle angle is another important anatomical parameter related to pedicle screw insertion. It has been reported that in normal spine, there are decreased pedicle angles in the thoracolumbar junction and the pedicles have almost neutral orientation at T11 and T12. ${ }^{16,25}$ In the current study, we found that in Lenke type 1 female AIS patients, there is also decreased transverse pedicle angle in the thoracolumbar junction and the smallest angulations were at T11 and T12. We also found that the transverse pedicle angle was significantly bigger on the concave side at the apical region of the curve (T7) which 
could be due to the intravertebral deformation that develops with rotation of the scoliotic spine. ${ }^{26,27}$ Meanwhile, the value of transverse pedicle angulation also showed substantial variations among different studies which may be related to the examiners' varying choice of the pedicular entry point. ${ }^{18}$ This highlights the importance of preoperative planning as no two Lenke type 1 deformities are alike. Similarities in transverse pedicle angle between curves should not be considered the rule.

Chord length is an important measurement in preventing anterior cortex perforation. Our study showed that at the apical region, the Lenke type 1 female AIS patients' chord length is slightly longer on the concave side than on the convex side which suggests that the concave side at the apex region may be able to accommodate a slightly longer pedicle screw. Similar findings have been reported in several other studies of scoliotic spine. ${ }^{18,28}$ This may be explained by the fact that with rotation of the scoliotic spine, the vertebral body drifts towards the concavity in the transverse plane which results in the slightly longer chord length on the concave side over the apical region. ${ }^{26}$

The strength of this study stems from the fact that we selected a homogeneous group of Lenke type 1 female AIS patients and collected the anatomic data from 539 pedicles based on $1 \mathrm{~mm}$ slice thickness CT scans. This provided a more accurate assessment comparing to the studies published previously. However, there are still limitations in our study. It would have been ideal if we could repeat the same measurements in all other Lenke type AIS patients and observe if there are differences of these parameters among different Lenke curve types. However, we were not able to do so in the current study due to the limited number of other Lenke curve type AIS patients in our patient cohort. Future studies will be needed to address this question.

In conclusion, our study showed that the vertebrae morphology in Lenke type 1 female AIS patients is substantially different from the vertebrae in normal spines especially in the apex and upper thoracic regions. These findings are consistent with some previous reports which did not distinguish between male and female patients. This suggests that gender does not play a major role in the vertebrae morphology pattern of AIS patients. Furthermore, recognizing these patterns is critical in order to optimize pedicle screw instrumentation and may allow for some leeway adjustments in the pedicle screw trajectory regardless of the methods of implantation. Based on the results of this small series, further studies are warranted to determine the vertebral morphology in a larger patient population and in other Lenke type AIS patients.

\section{References}

1. Roach JW. Adolescent idiopathic scoliosis. Orthop Clin North Am 1999;30:353-viiviii.

2. Cuartas E, Rasouli A, O'Brien M, Shufflebarger HL. Use of all-pedicle-screw constructs in the treatment of adolescent idiopathic scoliosis. J Am Acad Orthop Surg 2009;17:550-61.

3. Kim YJ, Lenke LG, Cho SK, Bridwell KH, Sides B, Blanke K. Comparative analysis of pedicle screw versus hook instrumentation in posterior spinal fusion of adolescent idiopathic scoliosis. Spine 2004;29:2040-8. 
4. Liljenqvist UR, Halm HF, Link TM. Pedicle screw instrumentation of the thoracic spine in idiopathic scoliosis. Spine 1997;22:2239-45.

5. Jutte PC, Castelein RM. Complications of pedicle screws in lumbar and lumbosacral fusions in consecutive primary operations. Eur Spine J 2002;11:594-8.

6. Kosmopoulos V, Schizas C. Pedicle screw placement accuracy: a meta-analysis. Spine 2007;32:E111-20.

7. Kotani Y, Abumi K, Ito M, Minami A. Improved accuracy of computer-assisted cervical pedicle screw insertion. Journal of neurosurgery 2003;99:257-63.

8. Podolsky DJ, Martin AR, Whyne CM, Massicotte EM, Hardisty MR, Ginsberg HJ. Exploring the role of 3-dimensional simulation in surgical training: feedback from a pilot study. J Spinal Disord Tech 2010;23:e70-4.

9. Rajasekaran S, Vidyadhara S, Ramesh P, Shetty AP. Randomized clinical study to compare the accuracy of navigated and non-navigated thoracic pedicle screws in deformity correction surgeries. Spine 2007;32:E56-64.

10. Tian NF, Huang QS, Zhou P, et al. Pedicle screw insertion accuracy with different assisted methods: a systematic review and meta-analysis of comparative studies. Eur Spine J 2010.

11. Chaynes P, Sol JC, Vaysse P, Becue J, Lagarrigue J. Vertebral pedicle anatomy in relation to pedicle screw fixation: a cadaver study. Surg Radiol Anat 2001;23:85-90.

12. Cinotti G, Gumina S, Ripani M, Postacchini F. Pedicle instrumentation in the thoracic spine. A morphometric and cadaveric study for placement of screws. Spine 1999;24:114-9.

13. Ebraheim NA, Xu R, Ahmad M, Yeasting RA. Projection of the thoracic pedicle and its morphometric analysis. Spine 1997;22:233-8.

14. Krag MH, Weaver DL, Beynnon BD, Haugh LD. Morphometry of the thoracic and lumbar spine related to transpedicular screw placement for surgical spinal fixation. Spine 1988;13:27-32.

15. Ugur HC, Attar A, Uz A, Tekdemir I, Egemen N, Genc Y. Thoracic pedicle: surgical anatomic evaluation and relations. J Spinal Disord 2001;14:39-45.

16. Vaccaro AR, Rizzolo SJ, Allardyce TJ, et al. Placement of pedicle screws in the thoracic spine. Part I: Morphometric analysis of the thoracic vertebrae. The Journal of bone and joint surgery 1995;77:1193-9.

17. Zindrick MR, Knight GW, Sartori MJ, Carnevale TJ, Patwardhan AG, Lorenz MA. Pedicle morphology of the immature thoracolumbar spine. Spine 2000;25:2726-35.

18. Liljenqvist UR, Link TM, Halm HF. Morphometric analysis of thoracic and lumbar vertebrae in idiopathic scoliosis. Spine 2000;25:1247-53.

19. Smith RM, Pool RD, Butt WP, Dickson RA. The transverse plane deformity of structural scoliosis. Spine 1991;16:1126-9.

20. Xiong B, Sevastik B, Willers U, Sevastik J, Hedlund R. Structural vertebral changes in the horizontal plane in idiopathic scoliosis and the long-term corrective effect of spine instrumentation. Eur Spine J 1995;4:11-4.

21. Lenke LG, Betz RR, Harms J, et al. Adolescent idiopathic scoliosis: a new classification to determine extent of spinal arthrodesis. The Journal of bone and joint surgery 2001;83-A:1169-81.

22. Parent S, Labelle H, Skalli W, de Guise J. Thoracic pedicle morphometry in vertebrae from scoliotic spines. Spine 2004;29:239-48.

23. Abul-Kasim K, Ohlin A. Patients with adolescent idiopathic scoliosis of Lenke type-1 curve exhibit specific pedicle width pattern. Eur Spine J 2012;21:57-63. 
24. Liljenqvist UR, Allkemper T, Hackenberg L, Link TM, Steinbeck J, Halm HF. Analysis of vertebral morphology in idiopathic scoliosis with use of magnetic resonance imaging and multiplanar reconstruction. The Journal of bone and joint surgery 2002;84-A:359-68.

25. Zindrick MR, Wiltse LL, Doornik A, et al. Analysis of the morphometric characteristics of the thoracic and lumbar pedicles. Spine 1987;12:160-6.

26. Upendra B, Meena D, Kandwal P, Ahmed A, Chowdhury B, Jayaswal A. Pedicle morphometry in patients with adolescent idiopathic scoliosis. Indian journal of orthopaedics 2010;44:169-76.

27. Kotwicki T, Napiontek M. Intravertebral deformation in idiopathic scoliosis: a transverse plane computer tomographic study. Journal of pediatric orthopedics 2008;28:225-9.

28. Takeshita K, Maruyama T, Chikuda H, et al. Diameter, length, and direction of pedicle screws for scoliotic spine: analysis by multiplanar reconstruction of computed tomography. Spine 2009;34:798-803.

29. Catan H, Buluc L, Anik Y, Ayyildiz E, Sarlak AY. Pedicle morphology of the thoracic spine in preadolescent idiopathic scoliosis: magnetic resonance supported analysis. Eur Spine J 2007;16:1203-8.

30. Li B, Jiang B, Fu Z, Zhang D, Wang T. Accurate determination of isthmus of lumbar pedicle: a morphometric study using reformatted computed tomographic images. Spine 2004;29:2438-44.

31. Asghar J, Samdani AF, Pahys JM, et al. Computed tomography evaluation of rotation correction in adolescent idiopathic scoliosis: a comparison of an all pedicle screw construct versus a hook-rod system. Spine 2009;34:804-7.

32. Hong JY, Suh SW, Easwar TR, Modi HN, Yang JH, Park JH. Evaluation of the Three Dimensional Deformities in Scoliosis Surgery with Computed Tomography: Efficacy and Relationship with Clinical Outcomes. Spine 2011.

33. O'Brien MF, Lenke LG, Mardjetko S, et al. Pedicle morphology in thoracic adolescent idiopathic scoliosis: is pedicle fixation an anatomically viable technique? Spine 2000;25:2285-93.

34. Ho EK, Upadhyay SS, Chan FL, Hsu LC, Leong JC. New methods of measuring vertebral rotation from computed tomographic scans. An intraobserver and interobserver study on girls with scoliosis. Spine 1993;18:1173-7.

35. Ho EK, Upadhyay SS, Ferris L, et al. A comparative study of computed tomographic and plain radiographic methods to measure vertebral rotation in adolescent idiopathic scoliosis. Spine 1992;17:771-4.

\section{Corresponding Author}

Isador H. Lieberman, Scoliosis and Spine Tumor Center, Texas Back Institute, Texas Health Presbyterian Hospital Plano, 6020 W. Parker Rd., Ste. 200a, Plano, TX 75093. ilieberman@texasback.com

\section{Disclosures}

The authors declare that there is no direct conflict of interest associated with this manuscript. No funds were received in support of this work. 
Copyright (C) 2014 ISASS - International Society for the Advancement of Spine Surgery.

To see more or order reprints or permissions, see http://ijssurgery.com. 